\title{
Normal Range of Left Ventricular 2-Dimensional Strain
}

\author{
- Japanese Ultrasound Speckle Tracking of \\ the Left Ventricle (JUSTICE) Study -
}

Kiyohiro Takigiku, MD; Masaaki Takeuchi, MD; Chisato Izumi, MD;

Satoshi Yuda, MD; Konomi Sakata, MD; Nobuyuki Ohte, MD; Kazuaki Tanabe, MD;

Satoshi Nakatani, MD on behalf of the JUSTICE investigators

\begin{abstract}
Background: To determine the normal range of left ventricular (LV) 2- dimensional (2-D) strain and vendor-specific differences, a multicenter prospective 2-D strain study endorsed by the Japanese Society of Echocardiography was conducted.
\end{abstract}

Methods and Results: 2-D speckle tracking analysis was performed on 817 healthy subjects (age range, 0-88 years); the images included 3 LV short axis and 3 apical views using an ultrasound system from 1 of the 3 different vendors $\left(V_{1}, n=333 ; V_{2}, n=330 ; V_{3}, n=337\right)$. With the 2-D speckle tracking software from each vendor, radial, circumferential and longitudinal strain were measured using an 18-segment model. Inter-vendor variability was also assessed in a subset of subjects. The feasibility for 2-D strain measurements was different among the 3 vendors $\left(\mathrm{V}_{1}, 83 \%\right.$; $\mathrm{V}_{2}$, $\left.70 \% ; \mathrm{V}_{3}, 88 \%, \mathrm{P}<0.01\right)$. The global radial $\left(\mathrm{V}_{1}, 54.6 \pm 12.6 \% ; \mathrm{V}_{2}, 36.3 \pm 8.2 \% ; \mathrm{V}_{3}, 51.4 \pm 8.0 \%\right)$, circumferential $\left(\mathrm{V}_{1}\right.$, $\left.-22.8 \pm 2.9 \% ; V_{2},-22.2 \pm 3.2 \% ; V_{3},-30.5 \pm 3.8 \%\right)$, and longitudinal $\left(V_{1},-21.3 \pm 2.1 \% ; V_{2},-18.9 \pm 2.5 \% ; V_{3},-19.9 \pm 2.4 \%\right)$ strain measurements were significantly different for each of the vendors. Segmental strain was also different between the 3 vendors. On inter-vendor analysis, vendor agreement ranged from mild to moderate.

Conclusions: Reference values are provided for normal 2-D strain for 3 different ultrasound vendors. Due to a low inter-vendor agreement, 2-D strain data are not interchangeable when conducting a longitudinal follow-up or a crosssectional assessment of LV function. (Circ J 2012; 76: 2623-2632)

Key Words: 2-D strain; Inter-vendor variability; Speckle tracking echocardiography

$\mathbf{T}$ wo-dimensional (2-D) speckle tracking echocardiography (STE) is being increasingly used for the quantification of global and regional left ventricular (LV) mechanics. ${ }^{1,2}$ Previous studies have validated the accuracy of STE against cardiac magnetic resonance imaging, a reference standard. ${ }^{3,4}$ The superiority of STE compared with LV ejection fraction has been reported in several clinical settings. ${ }^{5-7}$ The rapid advancement of computer technology allows us to measure layer-specific strain across the myocardium using some ultrasound systems and software. ${ }^{8-10}$

Despite the rapid adoption of this new technology, the normal range of LV 2-D strain has been traditionally measured in a small number of subjects. Little information exists regarding the equivalency of the normal ranges of LV 2-D strains when comparing ultrasound systems from different vendors; more- over, evidence for a good inter-vendor agreement of 2-D strain data from the same subjects remains to be elucidated. ${ }^{11-14}$ This inter-vendor agreement of 2-D strain is necessary for conducting a longitudinal follow-up or a cross-sectional assessment of the LV function using 2-D strain, because many ultrasound laboratories utilize a variety of ultrasound systems and analysis software packages from different vendors. Accordingly, in this multicenter study of healthy volunteers, the aims were to (1) establish the normal range of LV 2-D strain in a large number of healthy subjects; and (2) determine the inter-vendor, observer and test-retest variabilities of 2-D strain.

Received March 1, 2012; revised manuscript received June 13, 2012; accepted June 18, 2012; released online July 20 , 2012 Time for primary review: 20 days

Nagano Children's Hospital, Azumino (K. Takigiku); University of Occupational and Environmental Health, School of Medicine, Kitakyushu (M.T.); Tenri Hospital, Tenri (C.I.); Sapporo Medical University School of Medicine, Sapporo (S.Y.); Kyorin University School of Medicine, Tokyo (K.S.); Nagoya City University Graduate School of Medical Sciences, Nagoya (N.O.); Shimane University Faculty of Medicine, Izumo (K. Tanabe); and Osaka University Graduate School of Medicine, Suita (S.N.), Japan

Mailing address: Masaaki Takeuchi, MD, FASE, Second Department of Internal Medicine, University of Occupational and Environmental Health, School of Medicine, 1-1 Iseigaoka, Yahatanishi, Kitakyushu 807-8555, Japan. E-mail: takeuchi@med.uoeh-u.ac.jp

ISSN-1346-9843 doi:10.1253/circj.CJ-12-0264

All rights are reserved to the Japanese Circulation Society. For permissions, please e-mail: cj@j-circ.or.jp 


\section{Methods}

\section{Subjects}

Japanese Ultrasound Speckle Tracking of the Left Ventricle (JUSTICE) is a multicenter prospective 2-D strain study endorsed by the Japanese Society of Echocardiography (Principal Investigator: Satoshi Nakatani, MD). A total of 817 healthy subjects over a wide range of ages (0-88 years, 502 male) were enrolled. The eligibility criteria included (1) normal blood pressure and no history of hypertension at the time of examination; (2) absence of diabetes, hypercholesterolemia and/or cardiovascular disease; (3) no cardiac medications; and (4) ageand sex-based height and weight between the $25^{\text {th }}$ and $75^{\text {th }}$ percentiles. The subjects were recruited from 14 hospitals, and were primarily hospital employees, their relatives and/or volunteers who were recruited through advertising. All subjects underwent a physical examination and 2-D echocardiography to exclude those with valvular disease or the presence of regional wall motion abnormalities. The ethics committee from each of the hospitals approved the study protocol, and informed consent was obtained from all of the subjects.

\section{2-D Echocardiography}

Two-dimensional gray-scale harmonic images were obtained using an ultrasound system from 1 of 3 vendors $\left(V_{1}\right.$, Vivid 7 or Vivid E9, GE Healthcare; V2, iE33, Philips Medical Systems; $\mathrm{V}_{3}$, Artida or Aplio, Toshiba Medical Systems). The inter-vendor variability was determined using echocardiographic images in a subset of subjects using systems from 2 different vendors.

The 3 levels of the LV short axis view (basal, middle and apical) and 3 standard LV apical views during 2 or 3 consecutive cardiac cycles were acquired in the left lateral decubitus position during a breath hold and digitally stored on the hard disk. Care was taken to ensure that the basal short axis level contained the tip of the mitral valve and that the middle level of the short axis view contained papillary muscles. For the acquisition of the apical short axis view, the transducer position was moved 2 or 3 intercostal spaces more apically to ensure that the view did not contain a papillary muscle with a circular shape. The gain and the compression were adjusted to minimize the dropout of the LV endocardial and the epicardial borders. The depth and the sector angle were adjusted to include the LV, but the sector size was minimized to achieve a higher frame rate. To determine the timing of the cardiac events, the LV inflow and the outflow velocities were recorded using a pulsed-wave Doppler echocardiogram.

\section{Data}

All raw datasets were transferred to the core laboratory of University of Occupational and Environmental Health, and speckle tracking analysis was performed by an experienced observer blinded to the age and sex of each subject. The 2-D speckle tracking analysis was performed using speckle tracking software from each of the vendors (Echopac PC version 110.1.3, GE; QLAB, version 7.1, Philips; and Ultra-Extend, Toshiba) to obtain 3 strain measures (longitudinal, circumferential and radial strain). Detailed speckle tracking analysis for each vendor has been described elsewhere. ${ }^{8,9,15}$ After selecting 1 cardiac cycle with optimal image quality, the endocardial border in the end-systolic frame was manually traced. A region of interest was then drawn to include the entire myocardium. The software algorithm automatically segmented the LV into 6 equidistant segments and selected the appropriate speckles in the myocardium for tracking. The software algorithm then tracked the speckle patterns on a frame-by-frame basis using the vendor-specific tracking algorithm. Finally, the software automatically generated time-domain LV strain profiles for each of the 6 segments of each view from which the peak strain was measured. The peak strain at each of the 18 segments was determined. The level strain was calculated by averaging the segmental values (a maximum of 6 values per level) in the basal, middle and apical levels. The global strain was calculated by averaging the peak strain of the $18 \mathrm{LV}$ segments for each subject. To determine LV asynchronous contraction, we measured time from the $\mathrm{R}$ wave on the electrocardiogram to peak strain of the $18 \mathrm{LV}$ segments, and its SD was calculated. ${ }^{16,17}$ Because heart rate was different in each subject, the data are expressed as a percentage corrected by R-R interval.

Because the software from 2 of the 3 vendors did not provide an automated image tracking capability, the tracking quality was visually evaluated on the 2-D images. When the tracking was suboptimal, several attempts were made to adjust the regions of interest. If subjects had unreliable tracking quality in $>9$ of the 18 segments, these subjects were excluded from further analysis.

The image quality was also assessed and graded as follows: excellent (1) if $0-1$ of the LV endocardial borders of the 18 segments were poorly visible; good (2) if $2-3$ of the segments were poorly visible; fair (3) if 4-5 of the segments were poorly visible; and poor (4) if $>5$ of the segments were poorly visible.

\section{Observer Variability}

The intra-observer and inter-observer variabilities were assessed in 60 randomly selected subjects $(20$ subjects for each vendor), whereas the test-retest variability was assessed in 60 randomly selected subjects. For the intra-observer variability, datasets were analyzed again 1 week after the initial measurements. The inter-observer variability was determined by analyzing data from 2 separate observers. To determine the testretest variability, the parasternal short axis and the apical images were obtained within $1 \mathrm{~h}$ after the first measurement.

\section{Statistical Analysis}

The continuous data are expressed as mean \pm SD or median and interquartile range according to the data distribution. All statistical analysis was performed using commercially available software (JMP 9.0 or SPSS 16.0; SAS, CA, USA). One-way analysis of variance with post hoc comparison was performed to compare strain across the 3 groups. A linear model was used to assess the correlates of variation in the global longitudinal strain. Reliability was assessed using Bland-Altman analysis and intraclass correlation coefficient (ICC) with 95\% confidence interval. $\mathrm{P}<0.05$ was considered to be statistically significant.

\section{Results}

The subject demographic and fundamental echocardiography characteristics are listed in Table 1 . The mean frame rate on short axis view $\left(\mathrm{V}_{1}, 66 \pm 13 / \mathrm{s} ; \mathrm{V}_{2}, 65 \pm 10 / \mathrm{s} ; \mathrm{V}_{3}, 52 \pm 9 / \mathrm{s}\right)$ and apical view $\left(\mathrm{V}_{1}, 62 \pm 14 / \mathrm{s} ; \mathrm{V}_{2}, 62 \pm 9 / \mathrm{s} ; \mathrm{V}_{3}, 52 \pm 8 / \mathrm{s}\right)$ was significantly lower in $\mathrm{V}_{3}$ compared to $\mathrm{V}_{1}$ and $\mathrm{V}_{2}$. The image quality was better in $\mathrm{V}_{3}$ compared to $\mathrm{V}_{1}$ and $\mathrm{V}_{2}$ (mean image quality score: $\left.\mathrm{V}_{1}, 2.5 \pm 0.8 ; \mathrm{V}_{2}, 2.6 \pm 0.8 ; \mathrm{V}_{3}, 2.1 \pm 0.9\right)$. The feasibility of the strain measurements was significantly different between the 3 vendors $\left(\mathrm{V}_{1}, 83 \% ; \mathrm{V}_{2}, 70 \% ; \mathrm{V}_{3}, 88 \%, \mathrm{P}<0.01\right)$. Although the tracking feasibility depended on the image quality obtained from the 3 vendors, the degree of dependency was different (Figure 1). 


\begin{tabular}{|c|c|c|c|c|}
\hline & Overall & $\mathbf{V}_{\mathbf{1}}$ & $V_{2}$ & $\mathbf{V}_{3}$ \\
\hline No. subjects & 817 & 333 & 330 & 337 \\
\hline $\mathrm{M} / \mathrm{F}$ & $502 / 315$ & $208 / 125$ & $195 / 135$ & $235 / 102$ \\
\hline Age (years) & $36 \pm 18$ (range, 0-88) & $35 \pm 17$ & $33 \pm 19$ & $37 \pm 15$ \\
\hline Body surface area $\left(\mathrm{m}^{2}\right)$ & $1.57 \pm 0.35$ (range, $0.18-2.2)$ & $1.57 \pm 0.35$ & $1.51 \pm 0.38$ & $1.65 \pm 0.26$ \\
\hline Heart rate (beats/min) & $67 \pm 24$ & $68 \pm 16$ & $67 \pm 15$ & $65 \pm 11$ \\
\hline $\mathrm{SBP}(\mathrm{mmHg})$ & $119 \pm 15$ & $118 \pm 14$ & $119 \pm 15$ & $118 \pm 13$ \\
\hline $\mathrm{DBP}(\mathrm{mmHg})$ & $71 \pm 11$ & $70 \pm 11$ & $69 \pm 11$ & $69 \pm 11$ \\
\hline LVEDV (ml) & $83 \pm 26$ & $82 \pm 28$ & $82 \pm 26$ & $87 \pm 21$ \\
\hline LVESV (ml) & $30 \pm 11$ & $30 \pm 12$ & $31 \pm 12$ & $31 \pm 11$ \\
\hline LVEF (\%) & $63 \pm 7$ & $63 \pm 7$ & $63 \pm 7$ & $64 \pm 7$ \\
\hline E wave velocity $(\mathrm{cm} / \mathrm{s})$ & $82 \pm 19$ & $80 \pm 17$ & $87 \pm 20$ & $76 \pm 17$ \\
\hline A wave velocity $(\mathrm{cm} / \mathrm{s})$ & $53 \pm 17$ & $53 \pm 16$ & $53 \pm 17$ & $50 \pm 18$ \\
\hline E/A ratio & $1.7 \pm 0.6$ & $1.7 \pm 0.6$ & $1.8 \pm 0.7$ & $1.7 \pm 0.6$ \\
\hline
\end{tabular}

DBP, diastolic blood pressure; LVEDV, left ventricular end-diastolic volume; LVEF, left ventricular ejection fraction; LVESV, left ventricular end-systolic volume; SBP, systolic blood pressure.

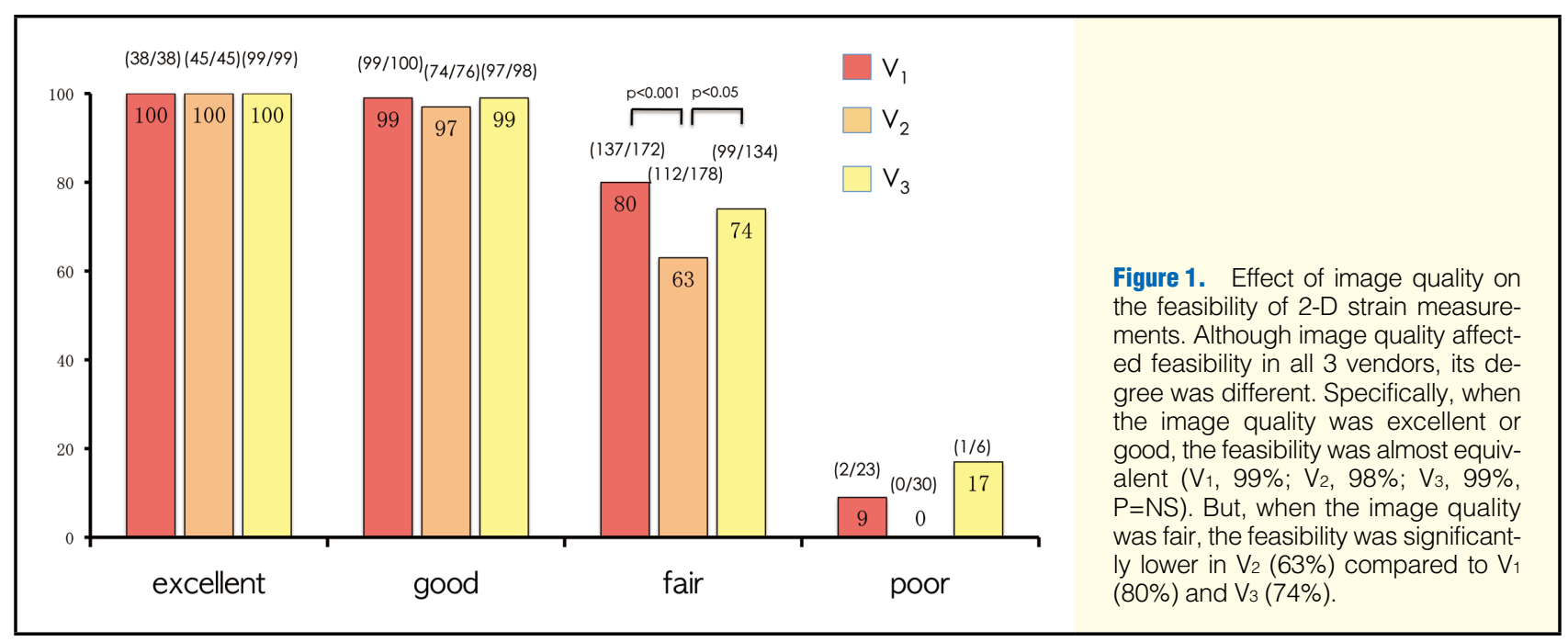

\section{Normal Strain}

Global strain from each of the 3 vendors was normally distributed (Figure 2A). Global strain and that at the basal, middle and apical levels of the LV myocardium are given Table 2. Global strain was significantly different between the 3 vendors. The most remarkable differences were noted in global radial strain. The same trend was also observed for the basal, middle and apical levels of the myocardium. Although the absolute values were different, longitudinal strain gradient from the basal level toward the apical level was uniformly observed in the data from all 3 vendors. The segmental strain for the $18 \mathrm{LV}$ segments is shown in Figure 2B. There were significant differences in the strain across all segments. LV dyssynchrony indices are also given in Table 2. Although the mean ranged from $3 \%$ to $5 \%$, strain dyssynchrony was significantly different among the 3 vendors.

\section{Effect of Anthropometric and Hemodynamic Variables on Global Longitudinal Strain}

Linear correlation between age, gender, body surface area, heart rate and blood pressure and global longitudinal strain for each vendor is given in Figure 3. Gender, body surface area and blood pressure were significantly correlated with global longitudinal strain in $\mathrm{V}_{1}$. In $\mathrm{V}_{2}$, age, gender, body surface area and blood pressure were correlates of the global longitudinal strain. In contrast, age and blood pressure were found to be the significant correlations in $\mathrm{V}_{3}$. The contribution of independent determinants, however, was only mild $\left(r^{2}=0.02-0.16\right)$. Table 3 lists the effects of age and gender on global longitudinal strain for each of the 3 vendors. Significant gender differences in longitudinal strain from the $3^{\text {rd }}$ to the $6^{\text {th }}$ decades were observed for $\mathrm{V}_{1}$, but no gender differences were noted in $\mathrm{V}_{3}$.

\section{Inter-Vendor and Observer Agreement}

The inter-vendor agreement was determined in 193 subjects ( $\mathrm{V}_{1}$ vs. $\mathrm{V}_{2}$ in 47 subjects; $\mathrm{V}_{1}$ vs. $\mathrm{V}_{3}$ in 96 subjects; and $\mathrm{V}_{2}$ vs. $\mathrm{V}_{3}$ in 50 subjects). Figure 4 shows the linear correlation and Bland-Altman analysis for inter-vender agreement of global radial, circumferential and longitudinal strain. In each 2-vendor comparison, the ICCs of global strain were poor to fair (Table 4). Not surprisingly, the ICC was the worst for the global radial strain, and the best for the global longitudinal strain. The inter-vendor agreements of LV dyssynchrony indices were also poor.

The ICCs for intra- and inter-observer variabilities and the test-retest variability were also assessed. The intra- and inter- 

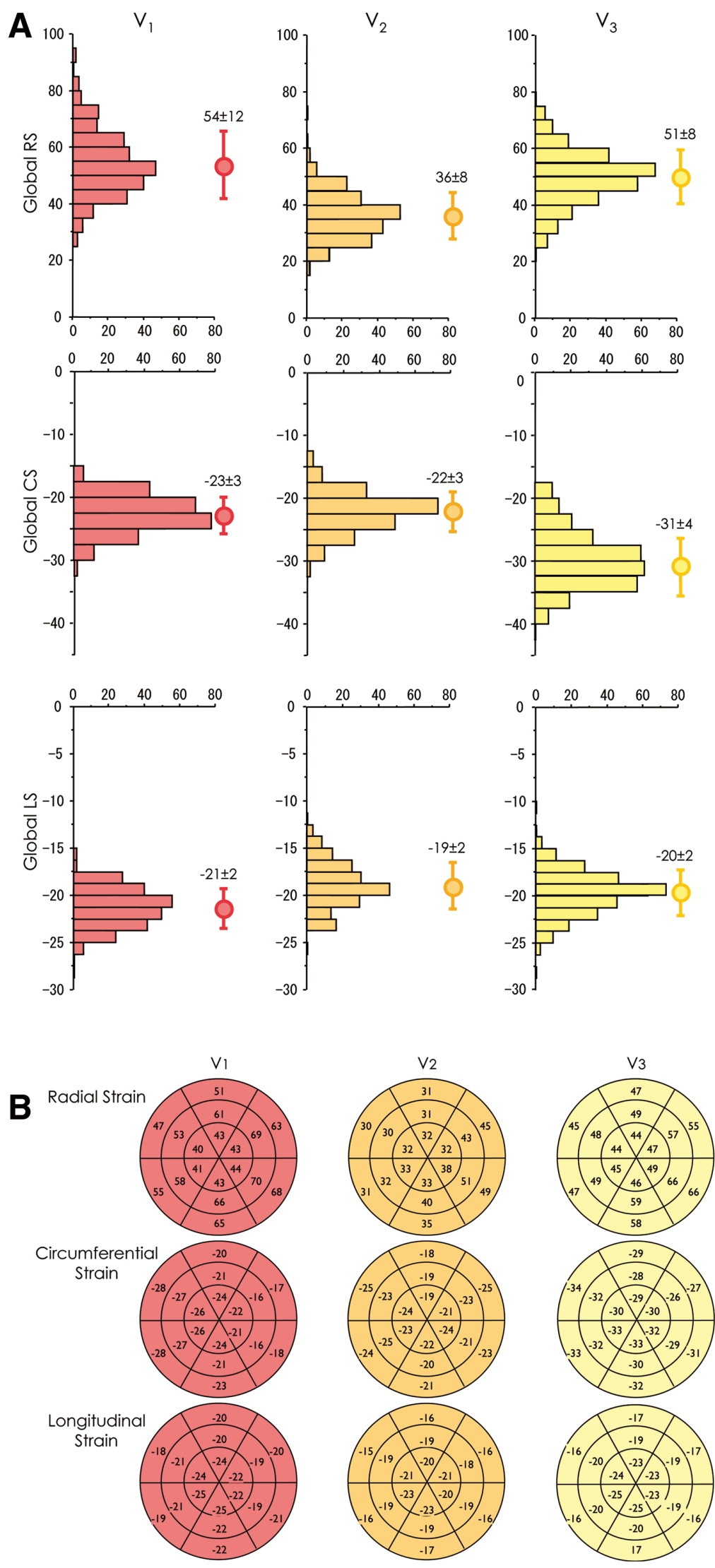

Figure 2. (A) 2-D strain measurement for each vendor. Data given as mean \pm SD. CS, circumferential strain; LS, longitudinal strain; RS, radial strain. (B) Bull's eye plots of segmental 2-D strain for the 3 vendors. 


\begin{tabular}{lcccc} 
Table 2. Global Strain and Average Strain at $\mathbf{3}$ LV Levels vs. Vendor & & \\
Radial strain & \multicolumn{1}{c}{$\mathbf{V}_{\mathbf{1}}$} & $\mathbf{V}_{\mathbf{2}}$ & $\mathbf{V}_{\mathbf{3}}$ & P value \\
Basal & & & & \\
Middle & $58.9 \pm 16.7$ & $36.2 \pm 10.7$ & $52.8 \pm 11.8$ & $<0.0001$ \\
Apical & $62.6 \pm 15.3$ & $37.2 \pm 10.7$ & $54.6 \pm 10.6$ & $<0.0001$ \\
P value & $41.4 \pm 16.6$ & $33.6 \pm 11.4$ & $45.3 \pm 12.6$ & $<0.0001$ \\
Global & $<0.0001$ & 0.0044 & $<0.0001$ & \\
Time to peak strain (ms) & $54.6 \pm 12.6$ & $36.3 \pm 8.2$ & $51.4 \pm 8.0$ & $<0.0001$ \\
SDTP (\%) & $399 \pm 46$ & $370 \pm 44$ & $379 \pm 38$ & $<0.0001$ \\
Circumferential strain & $4.0 \pm 1.6$ & $4.9 \pm 1.5$ & $4.0 \pm 1.7$ & $<0.0001$ \\
Basal & & & & $<$ \\
Middle & $-22.9 \pm 4.4$ & $-22.0 \pm 3.6$ & $-31.0 \pm 4.7$ & $<0.0001$ \\
Apical & $-21.7 \pm 3.4$ & $-21.8 \pm 3.8$ & $-29.3 \pm 4.2$ & $<0.0001$ \\
P value & $-23.6 \pm 4.2$ & $-22.0 \pm 3.8$ & $-30.9 \pm 6.1$ & $<0.0001$ \\
Global & $<0.0001$ & 0.0081 & $<0.0001$ & \\
Time to peak strain (ms) & $-22.8 \pm 2.9$ & $-22.2 \pm 3.2$ & $-30.5 \pm 3.8$ & $<0.0001$ \\
SDTP (\%) & $381 \pm 45$ & $356 \pm 41$ & $371 \pm 35$ & $<0.0001$ \\
Longitudinal strain & $4.7 \pm 1.6$ & $4.2 \pm 1.4$ & $3.1 \pm 1.4$ & $<0.0001$ \\
Basal & & & & $<$ \\
Middle & $-19.9 \pm 2.6$ & $-15.9 \pm 3.0$ & $-16.4 \pm 2.4$ & $<0.0001$ \\
Apical & $-20.6 \pm 2.1$ & $-19.0 \pm 2.7$ & $-19.5 \pm 2.8$ & $<0.0001$ \\
P value & $-23.6 \pm 3.4$ & $-21.6 \pm 3.4$ & $-23.6 \pm 3.7$ & $<0.0001$ \\
Global & $<0.0001$ & $<0.0001$ & $<0.0001$ & $<0.0001$ \\
Time to peak strain (ms) & $-21.3 \pm 2.1$ & $-18.9 \pm 2.5$ & $-19.9 \pm 2.4$ & $<0.0001$ \\
SDTP (\%) & $396 \pm 38$ & $376 \pm 41$ & $381 \pm 31$ & $<0.0001$ \\
\hline
\end{tabular}

SDTP, standard deviation of time to peak strain in 18-segment model.
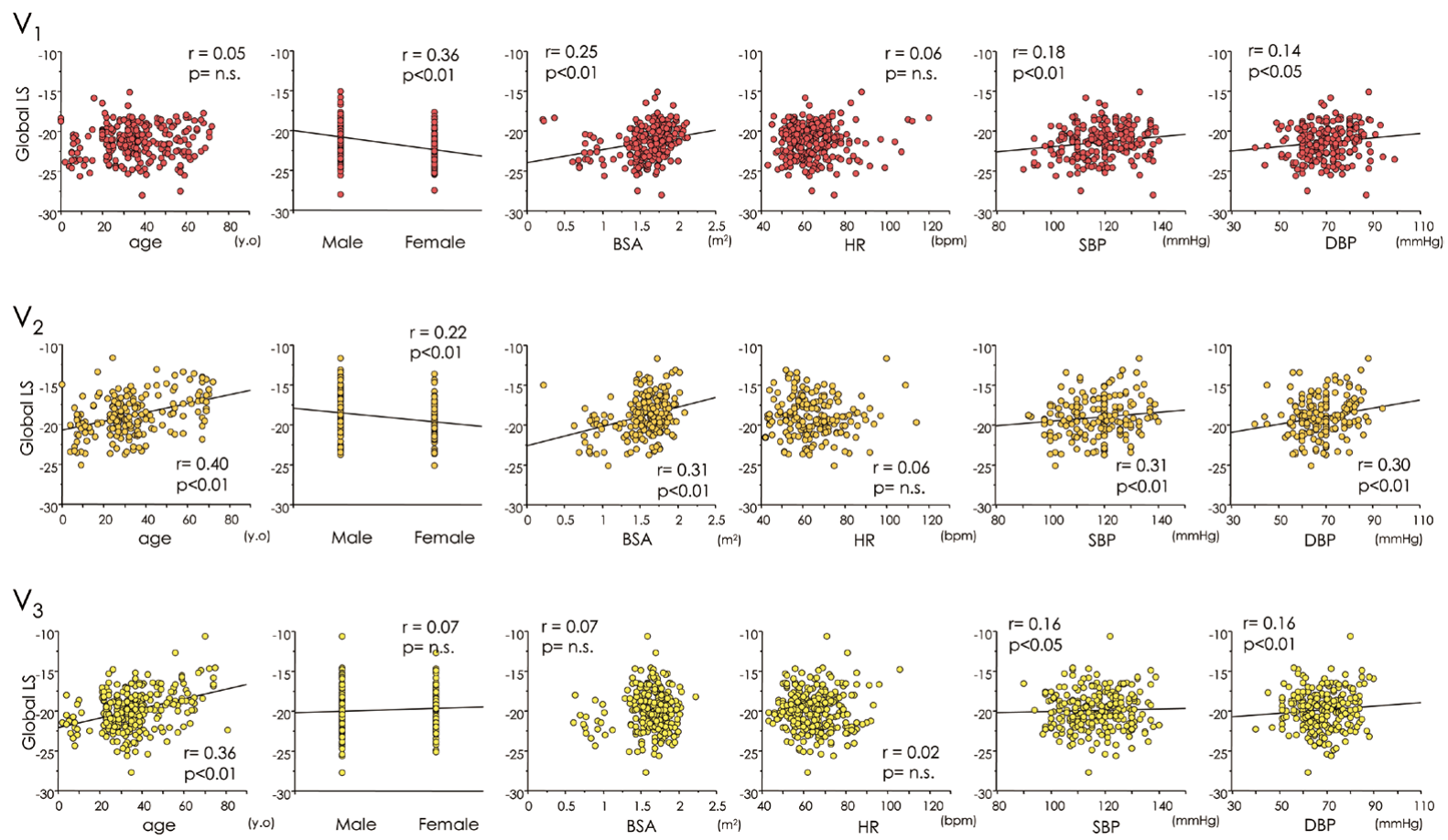

Figure 3. Linear correlation between anthropometric and hemodynamic variables and global longitudinal strain among 3 vendors. BSA, body surface area; DBP, diastolic blood pressure; HR, heart rate; LS, longitudinal strain; SBP, systolic blood pressure. 


\begin{tabular}{|c|c|c|c|c|c|c|c|}
\hline Age group & $\begin{array}{c}0-19 \\
\text { years }\end{array}$ & $\begin{array}{l}20-29 \\
\text { years }\end{array}$ & $\begin{array}{l}30-39 \\
\text { years }\end{array}$ & $\begin{array}{l}40-49 \\
\text { years }\end{array}$ & $\begin{array}{l}50-59 \\
\text { years }\end{array}$ & $\begin{array}{c}\geq 60 \\
\text { years }\end{array}$ & $P$ value \\
\hline \multicolumn{8}{|l|}{$V_{1}$} \\
\hline Overall & $-22.1 \pm 2.4$ & $-21.2 \pm 1.9$ & $-21.1 \pm 2.1$ & $-21.4 \pm 2.0$ & $-21.0 \pm 2.2$ & $-20.3 \pm 1.9$ & 0.0218 \\
\hline Male & $-21.7 \pm 3.1$ & $-20.9 \pm 1.9$ & $-20.6 \pm 1.9$ & $-20.9 \pm 1.8$ & $-21.0 \pm 1.9$ & $-19.7 \pm 1.4$ & 0.1982 \\
\hline Female & $-22.4 \pm 1.6$ & $-22.3 \pm 1.6$ & $-22.8 \pm 1.8$ & $-22.6 \pm 2.1$ & $-23.3 \pm 1.9$ & $-20.9 \pm 2.1$ & 0.0348 \\
\hline$P(M$ vs. $F)$ & 0.4292 & 0.0316 & $<0.0001$ & 0.0178 & 0.0029 & 0.1381 & \\
\hline \multicolumn{8}{|l|}{$V_{2}$} \\
\hline Overall & $-19.9 \pm 2.5$ & $-19.0 \pm 2.1$ & $-19.5 \pm 2.2$ & $-18.2 \pm 2.5$ & $-17.6 \pm 2.5$ & $-16.7 \pm 2.1$ & $<0.0001$ \\
\hline Male & $-19.4 \pm 2.7$ & $-18.8 \pm 2.0$ & $-19.1 \pm 2.3$ & $-17.9 \pm 2.8$ & $-16.9 \pm 2.3$ & $-15.8 \pm 1.4$ & 0.0019 \\
\hline Female & $-20.5 \pm 2.2$ & $-20.6 \pm 2.3$ & $-20.2 \pm 2.0$ & $-19.3 \pm 0.9$ & $-20.4 \pm 1.5$ & $-17.3 \pm 2.3$ & 0.0002 \\
\hline$P(M$ vs. $F)$ & 0.1349 & 0.0248 & 0.1083 & 0.4316 & 0.0294 & 0.0928 & \\
\hline \multicolumn{8}{|l|}{$V_{3}$} \\
\hline Overall & $-21.4 \pm 1.7$ & $-20.2 \pm 2.1$ & $-20.4 \pm 2.3$ & $-19.4 \pm 2.2$ & $-18.5 \pm 2.6$ & $-17.8 \pm 2.8$ & $<0.0001$ \\
\hline Male & $-21.6 \pm 2.0$ & $-20.2 \pm 2.0$ & $-20.4 \pm 2.2$ & $-19.8 \pm 2.3$ & $-18.7 \pm 2.6$ & $-16.3 \pm 3.1$ & $<0.0001$ \\
\hline Female & $-21.2 \pm 1.5$ & $-20.2 \pm 2.4$ & $-20.4 \pm 2.8$ & $-18.7 \pm 1.8$ & $-18.3 \pm 2.8$ & $-18.6 \pm 2.3$ & 0.0141 \\
\hline$P(M$ vs. $F)$ & 0.6076 & 0.9787 & 0.9201 & 0.1415 & 0.7374 & 0.0668 & \\
\hline
\end{tabular}

observer ICCs were always better than the inter-vendor agreement. Although intra-observer ICCs were always higher than inter-observer ICCs, they were somewhat different among the 3 vendors.

\section{Discussion}

The major findings are as follows: (1) the feasibility of the 2-D strain measurements was different depending on which ultrasound system was used; (2) the global and regional 2-D strain and LV dyssynchrony indices were significantly different between the 3 vendors (this finding requires the establishment of a normal range for 2-D strain for each vendor); and (3) the inter-vendor agreement was poor. This finding supports the lack of interchangeability of 2-D strain data from the same subject between ultrasound systems from different vendors longitudinally.

\section{Previous Studies}

After the first clinical report by Reisner et al demonstrating the utility of 2-D strain measurements, ${ }^{18}$ the number of publications in the medical literature regarding the clinical utility of 2-DSTE has grown rapidly. ${ }^{5-7,15}$ The routine use of 2-D strain in clinical practice requires the definition of a normal range, but the majority of the studies have defined their own normal ranges using a relatively small number of subjects who are of a limited age range. To our knowledge, only 3 studies have reported normal 2-D strain range in a large, adult population. Marwick et al reported an average LV peak systolic longitudinal strain of -18.6 with $0.1 \%$ of the limits of agreement in 242 healthy volunteers using a GE system. ${ }^{19}$ Although Dalen et al determined peak longitudinal strain in 1,266 healthy individuals, they used customized software that was not widely available. ${ }^{20}$ Another recent report described an average global longitudinal strain of $-20.6 \pm 2.6 \%$ and an average radial strain of $48.2 \pm 13.8 \%$ in 144 healthy subjects using a GE system. ${ }^{21}$ The radial strain from that report, however, was derived from only the middle level of the LV short-axis view.

Few studies have addressed the inter-vendor variability of 2-D strain measurements. ${ }^{11-14}$ Manovel et al performed 2-D speckle tracking analysis on 28 healthy adult subjects using ultrasound systems and software from GE and Toshiba, and found no significant vendor differences in the global longitu- dinal, circumferential or radial strain measurements. ${ }^{14}$ They also reported that global longitudinal strain had a more narrow limit of agreement ( -2.25 to 3.65$)$ compared to radial and circumferential strains and concluded that global longitudinal strain is a more robust parameter for evaluating myocardial function when a different cardiac ultrasound system is used for assessment. Koopman et al performed the same analysis on 34 children with or without cardiovascular disease using ultrasound systems from GE and Philips. ${ }^{13}$ They found that global longitudinal strain has a small bias (0.8) and narrower limit of agreement ( -4 to 6$)$ compared to circumferential and radial strain. But the correlation coefficient of global longitudinal strain between the 2 vendors was modest $(r=0.57)$, even though the enrolled subjects had a wide range of longitudinal strain.

\section{Current Study}

Although the fundamental concept of 2-D speckle tracking may be the same, 2-D image tracking ability on a frame-by-frame basis in each of the systems from the 3 vendors was different, resulting in a maximum difference of $18 \%$ in the feasibility between the 2 vendors. Image quality could affect the tracking feasibility observed in all of the systems from the different vendors (ie, good image-good tracking, bad image-bad tracking). The tracking ability at medium-range image quality, however, was significantly inferior in the Philips system compared to the systems from either GE or Toshiba. Therefore, it must be acknowledged that the contribution of image quality to tracking feasibility differs with vendor.

The normal range of 2-D strain in the present healthy subjects differed between the 3 vendors. As expected, the largest differences were observed in the global radial strain measurements, and the smallest differences were noted in the global longitudinal strain measurements. In addition to the different tracking algorithm used, image quality, post-processing and interpolation techniques, and the computation of the strain, the method of averaging data from the adjacent region and the different weighted averaging computational methods in each of the regions of interest increase the inaccuracies when calculating radial strain. The different values of global circumferential strain when comparing Toshiba to the 2 other vendors are related to the different regions of interest (the Toshiba system tracks and calculates the circumferential strain in the inner one-third of the myocardium). Although these points partially 

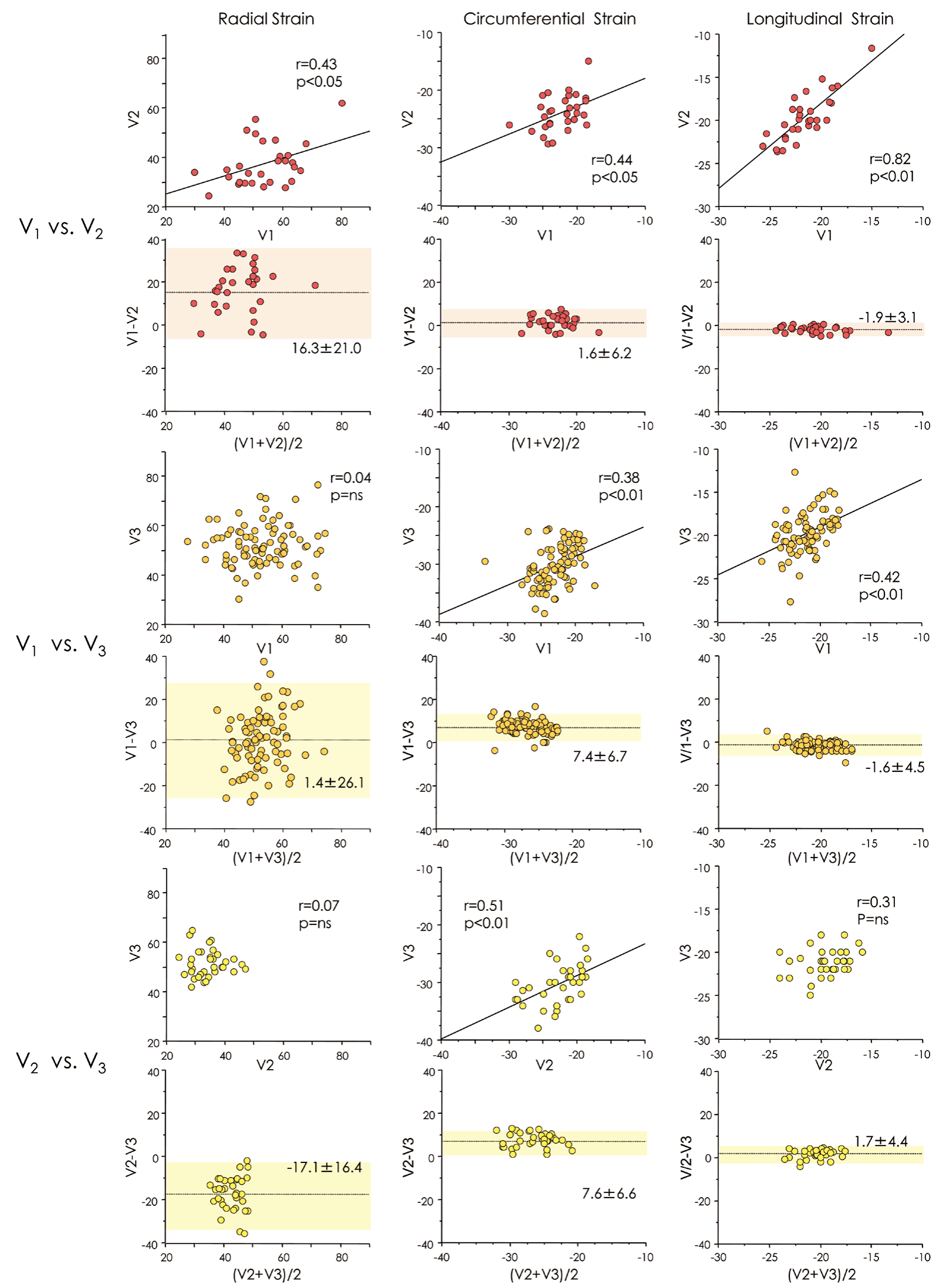

Figure 4. Inter-vendor agreement between 2 vendors for global radial, circumferential and longitudinal strain. Linear correlation and Bland-Altman plots are given (mean $\pm 2 S D$; hatched area, 95\% limits of agreement). 


\begin{tabular}{|c|c|c|c|c|c|}
\hline \multirow{2}{*}{\multicolumn{3}{|c|}{ Inter-vendor variability }} & \multirow[t]{3}{*}{$P$ value } & \multirow[t]{3}{*}{ Bias (95\% LOA) } & \multirow[t]{3}{*}{ ICC } \\
\hline & & & & & \\
\hline & $\mathbf{V}_{1}$ & $V_{2}$ & & & \\
\hline GRS & $53.7 \pm 10.7$ & $37.4 \pm 9.1$ & $<0.0001$ & $16.3(-4.7$ to 37.2$)$ & 0.18 \\
\hline SDTP & $3.7 \pm 1.7$ & $4.5 \pm 1.6$ & 0.0577 & -0.8 (-4.9 to 3.2$)$ & 0.20 \\
\hline GCS & $-22.4 \pm 2.8$ & $-24.0 \pm 3.1$ & 0.0109 & $1.6(-4.6$ to 7.7$)$ & 0.39 \\
\hline SDTP & $5.0 \pm 1.9$ & $4.0 \pm 1.1$ & 0.0401 & $0.9(-3.1$ to 5.0$)$ & 0.05 \\
\hline GLS & $-21.7 \pm 2.3$ & $-19.7 \pm 2.7$ & $<0.0001$ & $-1.9(-5.0$ to 1.1$)$ & 0.63 \\
\hline \multirow[t]{2}{*}{ SDTP } & $3.9 \pm 1.4$ & $5.6 \pm 1.6$ & 0.0024 & $-1.6(-6.5$ to 3.2$)$ & -0.22 \\
\hline & $\mathbf{V}_{1}$ & $\mathbf{V}_{3}$ & & & \\
\hline GRS & $53.6 \pm 10.4$ & $52.3 \pm 8.6$ & 0.3383 & $1.4(-24.7$ to 27.5$)$ & 0.02 \\
\hline SDTP & $4.1 \pm 1.5$ & $3.9 \pm 1.6$ & 0.2969 & $0.2(-3.5$ to 4.0$)$ & 0.19 \\
\hline GCS & $-22.8 \pm 2.4$ & $-30.2 \pm 3.6$ & $<0.0001$ & $7.4(0.7$ to 14.0$)$ & 0.10 \\
\hline SDTP & $4.6 \pm 1.6$ & $2.9 \pm 1.2$ & $<0.0001$ & $1.7(-1.6$ to 5.0$)$ & 0.15 \\
\hline GLS & $-21.4 \pm 1.8$ & $-19.8 \pm 2.4$ & $<0.0001$ & $-1.6(-6.0$ to 2.9$)$ & 0.31 \\
\hline \multirow[t]{2}{*}{ SDTP } & $3.8 \pm 1.4$ & $3.5 \pm 1.3$ & 0.0619 & $0.3(-2.5$ to 3.1$)$ & 0.44 \\
\hline & $\mathbf{V}_{2}$ & $\mathbf{V}_{3}$ & & & \\
\hline GRS & $34.4 \pm 5.8$ & $51.5 \pm 5.4$ & $<0.0001$ & $-17.1(-33.2$ to -0.9$)$ & -0.07 \\
\hline SDTP & $5.1 \pm 1.6$ & $3.9 \pm 1.4$ & 0.0036 & $1.1(-3.0$ to 5.4$)$ & -0.03 \\
\hline GCS & $-22.6 \pm 3.2$ & $-30.2 \pm 3.4$ & $<0.0001$ & $7.6(1.2$ to 14.1$)$ & 0.14 \\
\hline SDTP & $4.2 \pm 1.1$ & $2.7 \pm 1.0$ & $<0.0001$ & $1.5(-1.0$ to 4.0$)$ & 0.12 \\
\hline GLS & $-19.5 \pm 2.1$ & $-21.2 \pm 1.6$ & $<0.0001$ & $1.7(-2.5$ to 6.0$)$ & 0.20 \\
\hline \multirow[t]{2}{*}{ SDTP } & $4.9 \pm 1.5$ & $3.0 \pm 1.2$ & $<0.0001$ & $2.0(-1.9$ to 5.8$)$ & -0.01 \\
\hline & $1^{\text {st }}$ & $2^{\text {nd }}$ & & & \\
\hline \multicolumn{6}{|c|}{ Intra-observer variability } \\
\hline \multicolumn{6}{|l|}{$\mathbf{V}_{1}$} \\
\hline GRS & $53.8 \pm 13.8$ & $54.8 \pm 12.7$ & 0.2280 & $-1.0(-7.8$ to 5.9$)$ & 0.97 \\
\hline SDTP & $3.8 \pm 1.2$ & $4.1 \pm 1.0$ & 0.4470 & $-0.3(-2.8$ to 2.2$)$ & 0.36 \\
\hline GCS & $-23.1 \pm 3.1$ & $-23.0 \pm 2.8$ & 0.6936 & $-0.1(-2.2$ to 2.1$)$ & 0.93 \\
\hline SDTP & $4.3 \pm 1.6$ & $4.5 \pm 1.5$ & 0.6918 & $-0.2(-3.0$ to 2.6$)$ & 0.60 \\
\hline GLS & $-21.3 \pm 1.9$ & $-21.7 \pm 2.1$ & 0.0274 & $0.4(-1.1$ to 1.9$)$ & 0.91 \\
\hline SDTP & $3.5 \pm 1.1$ & $3.2 \pm 1.3$ & 0.4053 & $0.2(-1.4$ to 1.8$)$ & 0.79 \\
\hline \multicolumn{6}{|l|}{$\mathbf{V}_{2}$} \\
\hline GRS & $37.1 \pm 4.2$ & $37.5 \pm 4.1$ & 0.6394 & $-0.4(-8.4$ to 7.6$)$ & 0.54 \\
\hline SDTP & $5.0 \pm 0.7$ & $4.7 \pm 1.2$ & 0.4915 & 0.3 (-2.3 to 2.9$)$ & 0.12 \\
\hline GCS & $-22.2 \pm 3.3$ & $-22.4 \pm 2.8$ & 0.5053 & $0.2(-2.6$ to 3.0$)$ & 0.90 \\
\hline SDTP & $4.4 \pm 1.0$ & $4.4 \pm 0.7$ & 0.9969 & $0.0(-1.7$ to 1.7$)$ & 0.52 \\
\hline GLS & $-19.2 \pm 1.7$ & $-19.0 \pm 1.7$ & 0.4363 & $-0.1(-1.8$ to 1.5$)$ & 0.89 \\
\hline SDTP & $4.3 \pm 1.0$ & $4.5 \pm 0.6$ & 0.3067 & $-0.2(-1.4$ to 1.0$)$ & 0.75 \\
\hline \multicolumn{6}{|l|}{$\mathbf{V}_{3}$} \\
\hline GRS & $50.8 \pm 5.5$ & $50.3 \pm 5.5$ & 0.7330 & $0.5(-12.2$ to 13.1$)$ & 0.34 \\
\hline SDTP & $3.3 \pm 1.2$ & $3.5 \pm 1.9$ & 0.6328 & $-0.2(-2.1$ to 1.8$)$ & 0.81 \\
\hline GCS & $-31.7 \pm 3.2$ & $-32.1 \pm 3.3$ & 0.3875 & $0.4(-3.7$ to 4.5$)$ & 0.79 \\
\hline SDTP & $2.1 \pm 0.9$ & $2.3 \pm 0.7$ & 0.3335 & $-0.1(-1.0$ to 0.7$)$ & 0.83 \\
\hline GLS & $-21.6 \pm 1.6$ & $-21.6 \pm 1.6$ & 0.9414 & $0.0(-2.7$ to 2.6$)$ & 0.60 \\
\hline \multirow[t]{2}{*}{ SDTP } & $2.7 \pm 1.8$ & $2.5 \pm 1.0$ & 0.7409 & $0.2(-3.8$ to 4.3$)$ & 0.02 \\
\hline & Observer 1 & Observer 2 & & & \\
\hline \multirow{2}{*}{\multicolumn{6}{|c|}{$\begin{array}{l}\text { Inter-observer variability } \\
V_{1}\end{array}$}} \\
\hline & & & & & \\
\hline GRS & $53.8 \pm 13.3$ & $53.2 \pm 13.6$ & 0.6870 & $0.5(-10.9$ to 12.0$)$ & 0.91 \\
\hline SDTP & $3.8 \pm 1.2$ & $4.0 \pm 1.1$ & 0.5506 & $-0.2(-2.0$ to 1.7$)$ & 0.68 \\
\hline GCS & $-23.2 \pm 3.4$ & $-24.0 \pm 2.6$ & 0.0786 & $0.8(-3.1$ to 4.7$)$ & 0.79 \\
\hline SDTP & $4.3 \pm 1.6$ & $3.9 \pm 1.5$ & 0.4737 & $0.5(-2.7$ to 3.6$)$ & 0.43 \\
\hline GLS & $-21.3 \pm 1.9$ & $-21.3 \pm 2.1$ & 0.9618 & $0.0(-2.1$ to 2.1$)$ & 0.86 \\
\hline SDTP & $3.5 \pm 1.1$ & $2.0 \pm 1.0$ & 0.0086 & 1.5 (-1.3 to 4.2$)$ & 0.04 \\
\hline
\end{tabular}

(Table 4 continued the next page.) 


\begin{tabular}{|c|c|c|c|c|c|}
\hline & Observer 1 & Observer 2 & $P$ value & Bias (95\% LOA) & ICC \\
\hline \multicolumn{6}{|l|}{$V_{2}$} \\
\hline GRS & $37.1 \pm 4.2$ & $38.1 \pm 7.8$ & 0.4890 & $-1.1(-14.1$ to 12.0$)$ & 0.42 \\
\hline SDTP & $5.0 \pm 0.7$ & $4.8 \pm 1.0$ & 0.7150 & 0.1 (-1.9 to 2.2$)$ & 0.28 \\
\hline GCS & $-22.2 \pm 3.3$ & $-22.5 \pm 2.5$ & 0.5728 & $0.3(-3.9$ to 4.5$)$ & 0.74 \\
\hline SDTP & $4.4 \pm 1.0$ & $4.6 \pm 0.6$ & 0.3229 & $-0.2(-1.5$ to 1.1$)$ & 0.67 \\
\hline GLS & $-19.2 \pm 1.7$ & $-18.8 \pm 2.2$ & 0.2435 & $-0.4(-3.4$ to 2.6$)$ & 0.70 \\
\hline SDTP & $4.3 \pm 1.0$ & $4.6 \pm 0.8$ & 0.0555 & $-0.4(-1.6$ to 0.8$)$ & 0.73 \\
\hline \multicolumn{6}{|l|}{$\mathbf{V}_{3}$} \\
\hline GRS & $50.7 \pm 5.5$ & $54.2 \pm 7.4$ & 0.0562 & $-3.4(-18.3$ to 11.4$)$ & 0.34 \\
\hline SDTP & $3.3 \pm 1.2$ & $3.5 \pm 0.7$ & 0.4751 & $-0.2(-1.8$ to 1.4$)$ & 0.67 \\
\hline GCS & $-31.7 \pm 3.2$ & $-32.1 \pm 3.2$ & 0.5803 & $0.4(-5.3$ to 6.0$)$ & 0.60 \\
\hline SDTP & $2.1 \pm 0.9$ & $3.0 \pm 0.7$ & 0.0027 & $-0.9(-2.2$ to 0.5$)$ & 0.40 \\
\hline GLS & $-21.6 \pm 1.6$ & $-20.6 \pm 2.0$ & 0.0294 & $-1.0(-4.8$ to 2.8$)$ & 0.43 \\
\hline \multirow[t]{2}{*}{ SDTP } & $2.7 \pm 1.8$ & $3.0 \pm 1.1$ & 0.7083 & $-0.2(-4.2$ to 3.7$)$ & 0.06 \\
\hline & $1^{\text {st }}$ & $2^{\text {nd }}$ & & & \\
\hline \multicolumn{6}{|c|}{ Test-retest variability } \\
\hline \multicolumn{6}{|l|}{$V_{1}$} \\
\hline GRS & $51.3 \pm 10.3$ & $52.0 \pm 8.6$ & 0.6320 & $-0.6(-12.3$ to 11.1$)$ & 0.81 \\
\hline SDTP & $3.6 \pm 1.2$ & $3.8 \pm 1.0$ & 0.3887 & $-0.2(-1.6$ to 1.2$)$ & 0.80 \\
\hline GCS & $-22.6 \pm 2.5$ & $-23.2 \pm 2.8$ & 0.1379 & $0.6(-2.8$ to 4.1$)$ & 0.76 \\
\hline SDTP & $4.6 \pm 1.6$ & $4.3 \pm 1.2$ & 0.3565 & $0.4(-1.9$ to 2.6$)$ & 0.67 \\
\hline GLS & $-21.2 \pm 2.2$ & $-21.4 \pm 2.3$ & 0.2901 & $0.3(-1.9$ to 2.4$)$ & 0.88 \\
\hline SDTP & $4.1 \pm 1.2$ & $3.6 \pm 1.3$ & 0.0980 & $0.5(-1.2$ to 2.1$)$ & 0.73 \\
\hline \multicolumn{6}{|l|}{$V_{2}$} \\
\hline GRS & $38.6 \pm 7.1$ & $38.1 \pm 6.1$ & 0.7221 & $0.5(-12.1$ to 13.1$)$ & 0.54 \\
\hline SDTP & $4.9 \pm 1.5$ & $5.2 \pm 2.0$ & 0.6637 & $-0.3(-4.2$ to 3.6$)$ & 0.41 \\
\hline GCS & $-23.8 \pm 4.0$ & $-23.5 \pm 3.3$ & 0.4798 & $-0.3(-4.1$ to 3.4$)$ & 0.87 \\
\hline SDTP & $4.0 \pm 1.2$ & $3.9 \pm 1.4$ & 0.7883 & $0.1(-1.9$ to 2.0$)$ & 0.73 \\
\hline GLS & $-20.1 \pm 2.6$ & $-20.3 \pm 2.5$ & 0.7197 & $0.1(-2.8$ to 3.0$)$ & 0.83 \\
\hline SDTP & $5.6 \pm 1.5$ & $5.4 \pm 1.5$ & 0.2921 & $0.3(-1.3$ to 1.9$)$ & 0.85 \\
\hline \multicolumn{6}{|l|}{$V_{3}$} \\
\hline GRS & $53.6 \pm 7.2$ & $54.4 \pm 7.2$ & 0.7612 & $-0.8(-22.1$ to 20.6$)$ & 0.16 \\
\hline SDTP & $3.9 \pm 1.4$ & $4.9 \pm 1.7$ & 0.2362 & $-1.0(-5.8$ to 3.8$)$ & -0.31 \\
\hline GCS & $-32.6 \pm 3.7$ & $-33.4 \pm 4.3$ & 0.1847 & $0.7(-4.0$ to 5.5$)$ & 0.81 \\
\hline SDTP & $3.2 \pm 1.2$ & $3.6 \pm 1.3$ & 0.5397 & $-0.4(-4.1$ to 3.3$)$ & -0.14 \\
\hline GLS & $-20.6 \pm 1.6$ & $-21.1 \pm 1.2$ & 0.1488 & $0.6(-2.7$ to 3.8$)$ & 0.32 \\
\hline SDTP & $3.5 \pm 0.9$ & $3.3 \pm 1.0$ & 0.5761 & $0.2(-1.9$ to 2.2$)$ & 0.38 \\
\hline
\end{tabular}

GCS, global circumferential strain; GLS, global longitudinal strain; GRS, global radial strain; ICC, intraclass correlation coefficient; LOA, limits of agreement; SDTP, standard deviation of time to peak strain in 18-segment model (\%).

contribute to the difference, the detailed algorithms for 2-D speckle tracking used in the systems from individual vendors are proprietary, and not visible to the user. We also observed significant vendor differences in age and gender dependency on global longitudinal strain, meaning that different ultrasound systems could provide contradictory results.

The low 2-D strain ICC measured from the same subjects using different systems raises a caution about the clinical application of 2DSTE. Systems from different vendors are not interchangeable when acquiring and analyzing 2-D strain data to assess longitudinal changes in the LV function from the same subjects. Although the highest ICC of global longitudinal strain indicates that longitudinal strain is less subject to variation, relatively larger limits of agreement cannot validate whether the observed difference is clinically relevant. As noted in a previous reported editorial review, if global 2-D strain is to be used in a longitudinal follow-up, the baseline and the follow-up images should be obtained using the same ultrasound system. ${ }^{22}$

\section{Study Limitations}

Several study limitations should be addressed. We did not have any gold standard with which to confirm the accuracy of 2-D strain measurements in each vendor-specific system. Because the validation of 2-D strain against tagged cardiac magnetic resonance imaging in a large number of healthy subjects is difficult, we determined the technique reliability and established a normal range of 2-D strain separately for each of the 3 ultrasound vendors. The inter-vendor variability was not tested among the 3 ultrasound vendors because none of the participating hospitals had ultrasound systems from all 3 of the specified vendors. But the number of subjects used to determine the ICCs between 2 vendors seemed sufficiently large and was larger than that used in previous reports. ${ }^{11-14}$ 


\section{Conclusions}

We have established the normal range of 2-D strain for each of the ultrasound systems from 3 vendors in a large healthy subject group. The present results provide a reference value for 2-D strain, which is useful in future clinical research when using the 3 specified ultrasound vendors. The low ICCs of 2-D strain across the different vendors suggest that the system and software from the same vendor should be used for a longitudinal follow-up in the same patients or a cross-sectional study.

\section{Acknowledgments}

We thank the following institutions and investigators for participating in this study. Satoshi Yamada, MD, Hokkaido University Graduate School of Medicine; Yoshihiro Seo, MD, Faculty of Medicine, University of Tsukuba; Kansei Uno, MD and Koichi Kimura, MD, Graduate School of Medicine, University of Tokyo; Yuji Kasamaki, MD, Nihon University School of Medicine, Itabashi Hospital; Kentaro Omoya, MD, Gifu Prefectural General Medical Center; Takeshi Hozumi, MD, Osaka City University, Graduate School of Medicine. We also thank Drs Kyoko Kaku and Seiichi Tazawa for preparing the datasets.

\section{Disclosures}

There were no relationships with industry.

\section{References}

1. Mor-Avi V, Lang RM, Badano LP, Belohlavek M, Cardim NM, Derumeaux G, et al. Current and evolving echocardiographic techniques for the quantitative evaluation of cardiac mechanics: ASE/ EAE consensus statement on methodology and indications. J Am Soc Echocardiogr 2011; 24: 277-313.

2. Perk G, Tunick PA, Kronzon I. Non-Doppler two-dimensional strain imaging by echocardiography: From technical considerations to clinical applications. J Am Soc Echocardiogr 2007; 20: 234-243.

3. Amundsen BH, Helle-Valle T, Edvardsen T, Torp H, Crosby J, Lyseggen E, et al. Noninvasive myocardial strain measurement by speckle tracking echocardiography. J Am Coll Cardiol 2006; 47: 789793.

4. Langeland S, D'hooge J, Wouters PF, Leather HA, Claus P, Bijnens $\mathrm{B}$, et al. Experimental validation of a new ultrasound method for the simultaneous assessment of radial and longitudinal myocardial deformation independent of insonation angle. Circulation 2005; 112: $2157-2162$.

5. Gjesdal O, Hopp E, Vartdal T, Lunde K, Helle-Valle T, Aakhus S, et al. Global longitudinal strain measured by two-dimensional speckle tracking echocardiography is closely related to myocardial infarct size in chronic ischaemic heart disease. Clin Sci 2007; 113: 287.

6. Haruki N, Takeuchi M, Kanazawa Y, Tsubota N, Shintome R, Nakai $\mathrm{H}$, et al. Continuous positive airway pressure ameliorates sleep-induced subclinical left ventricular systolic dysfunction: Demonstration by two-dimensional speckle-tracking echocardiography. Eur $J$ Echocardiogr 2010; 11: 352-358.

7. Nakai H, Takeuchi M, Nishikage T, Lang RM, Otsuji Y. Subclinical left ventricular dysfunction in asymptomatic diabetic patients assessed by two-dimensional speckle tracking echocardiography: Correlation with diabetic duration. Eur J Echocardiogr 2009; 10: 926-932.

8. Goffinet C, Chenot F, Robert A, Pouleur AC, le Polain de Waroux JB, Vancrayenest D, et al. Assessment of subendocardial vs. subepicardial left ventricular rotation and twist using two-dimensional speckle tracking echocardiography: Comparison with tagged cardiac magnetic resonance. Eur Heart J 2009; 30: 608-617.

9. Ishizu T, Seo Y, Enomoto Y, Sugimori H, Yamamoto M, Machino T, et al. Experimental validation of left ventricular transmural strain gradient with echocardiographic two-dimensional speckle tracking imaging. Eur J Echocardiogr 2010; 11: 377-385.

10. Leitman M, Lysiansky M, Lysyansky P, Friedman Z, Tyomkin V, Adam D, et al. Circumferential and longitudinal strain in 3 myocardial layers in normal subjects and in patients with regional left ventricular dysfunction. J Am Soc Echocardiogr 2010; 23: 64-70.

11. Bansal M, Cho GY, Chan J, Leano R, Haluska BA, Marwick TH. Feasibility and accuracy of different techniques of two-dimensional speckle based strain and validation with harmonic phase magnetic resonance imaging. J Am Soc Echocardiogr 2008; 21: 1318-1325.

12. Biaggi P, Carasso S, Garceau P, Greutmann M, Gruner C, Tsang W, et al. Comparison of two different speckle tracking software systems: Does the method matter? Echocardiography 2011; 28: 539-547.

13. Koopman LP, Slorach C, Hui W, Manlhiot C, Friedberg MK, Jaeggi ET, et al. Comparison between different speckle tracking and color tissue Doppler techniques to measure global and regional myocardial deformation in children. J Am Soc Echocardiogr 2010; 23: 919-928.

14. Manovel A, Dawson D, Smith B, Nihoyannopoulos P. Assessment of left ventricular function by different speckle-tracking software. Eur J Echocardiogr 2010; 11: 417-421.

15. Leitman M, Lysyansky P, Sidenko S, Shir V, Peleg E, Binenbaum M, et al. Two-dimensional strain: A novel software for real-time quantitative echocardiographic assessment of myocardial function. $J \mathrm{Am}$ Soc Echocardiogr 2004; 17: 1021 -1029.

16. Sakamaki F, Seo Y, Ishizu T, Yanaka S, Atsumi A, Yamamoto M, et al. Tissue Doppler imaging dyssynchrony parameter derived from the myocardial active wall motion improves prediction of responders for cardiac resynchronization therapy. Circ J 2012; 76: 689-697.

17. Yamawaki K, Tanaka H, Matsumoto K, Hiraishi M, Miyoshi T, Kaneko A, et al. Impact of left ventricular afterload on longitudinal dyssynchrony in patients with severe aortic stenosis and preserved ejection fraction. Circ J 2012; 76: 744-751.

18. Reisner SA, Lysyansky P, Agmon Y, Mutlak D, Lessick J, Friedman Z. Global longitudinal strain: A novel index of left ventricular systolic function. J Am Soc Echocardiogr 2004; 17: 630-633.

19. Marwick TH, Leano RL, Brown J, Sun JP, Hoffmann R, Lysyansky $\mathrm{P}$, et al. Myocardial strain measurement with 2-dimensional speckletracking echocardiography: Definition of normal range. JACC Cardiovasc Imaging 2009; 2: 80-84.

20. Dalen H, Thorstensen A, Aase SA, Ingul CB, Torp H, Vatten LJ, et al. Segmental and global longitudinal strain and strain rate based on echocardiography of 1266 healthy individuals: The HUNT study in Norway. Eur J Echocardiogr 2010; 11: 176-183.

21. Reckefuss N, Butz T, Horstkotte D, Faber L. Evaluation of longitudinal and radial left ventricular function by two-dimensional speckletracking echocardiography in a large cohort of normal probands. Int $J$ Cardiovasc Imaging. 2010; 27: 515-526.

22. Marwick TH. Consistency of myocardial deformation imaging between vendors. Eur J Echocardiogr 2010; 11: 414-416. 